\title{
ANÁLISE DA CONTRIBUIÇÃO DAS ATIVIDADES DE LONGA DURAÇÃO NO MOVIMENTO ESCOTEIRO PARA A EDUCAÇÃO AMBIENTAL DE JOVENS
}

\author{
Christie Sototuka; Rosana Silva
}

\begin{abstract}
RESUMO
Diante do pouco conhecimento científico sobre a contribuição da educação não formal do Movimento Escoteiro (ME) na educação ambiental de jovens, investigamos atividades ao ar livre de longa duração para tentar entender 1) o que jovens de 15 a 17 anos lembram e valorizam nas suas experiências e 2) se a participação nessas atividades influencia em sua educação ambiental em termos de conceitos, valores e formas de participação diferenciadas no cotidiano. Foram entrevistados 15 jovens de um Grupo Escoteiro de São Paulo por meio de questionário com perguntas abertas. Os resultados demonstram que as amizades e o contato com a natureza são fatores positivos importantes para participação nas atividades, que os jovens transferem algumas atitudes para o cotidiano e que apresentam visões globalizantes e naturalistas de meio ambiente. Entretanto, as atitudes dos jovens ainda são individuais, sem uma visão crítica da relação humana com o meio ambiente ou aos aspectos socioambientais, que ainda precisam ser melhor trabalhados nessas atividades.
\end{abstract}

Palavras-chave: movimento escoteiro, atividades ao ar livre, educação ambiental não formal, concepções

\begin{abstract}
In face of the lack of scientific knowledge on the contribution of Scout Movement's non formal education to environmental education of young people, we investigated its relation to long duration outdoor activities to attempt to understand 1) what young people aged 15 to 17 years old remember and value in their experiences and 2) if their participation in these activities influence their environmental education in terms of concepts, virtues and forms of differentiated participation in daily life. Fifteen teenagers from a scout group in São Paulo were interviewed using a questionnaire with open-ended questions. Results demonstrate that contact with nature and friendships are important positive factors for activities, and that young people shift attitudes in everyday life and display global and naturalist environmental visions. However, young people's attitudes are individualist, lacking a critical sense on the relationship between humans and the environment, which still needs to be developed.
\end{abstract}

Keywords: scout movement, outdoor education, non-formal environmental education, conceptions

\section{INTRODUÇÃO}

O Movimento Escoteiro (ME) oferece mundialmente diversas atividades para jovens de 5 a 21 anos e, no Brasil, dos 6,5 aos 21 anos. O jovem escoteiro realiza a maioria das atividades semanalmente em um local perto de sua residência e também algumas excursões em locais mais afastados, os quais podem durar alguns dias. O ME é um grande atrativo para jovens por causa das diversas atividades que proporciona, porém não deve ser confundido com atividades de recreação, mas reconhecido como movimento educativo. Por isso, é importante avaliar por meio de pesquisas se as vivências previstas no escotismo contribuem para o aprendizado dos jovens, em sua 
relação com o meio ambiente e, mais especificamente, para a Educação Ambiental (EA).

O Escotismo começou em 1907, com o britânico Robert Stephenson Smyth Baden-Powell, um tenente-general que quis testar se seus métodos de treinamento eram interessantes para rapazes e poderiam ser usados por algumas organizações de jovens da época. O teste foi feito com 20 meninos em um acampamento na Ilha de Brownsea, Inglaterra, e, após o seu sucesso, Baden-Powell publicou o livro Escotismo para Rapazes. Esse livro acarretou na organização voluntária e independente de diversos grupos jovens que adotaram o nome de Escoteiros. A partir de então, a obra foi traduzida para diversas línguas e espalhou-se por diversos países. Inicialmente, o programa tinha foco em rapazes, mas em 1910, Baden-Powell e sua irmã Lady Agnes criaram um programa para meninas, o Bandeirantismo, e para as crianças, o Ramo Lobo em 1916 (Wosm, 2016). Em 1910, foi fundado o Primeiro Centro de Boy Scouts do Brasil e já em 1917 foi sancionado o Decreto do Poder Legislativo no 3297 que no Art. $1^{\circ}$ estabelecia que "São considerados de utilidade pública, para todos os efeitos, as associações brasileiras de escoteiros com sede no país”. Décadas depois, em 1946, o Decreto-Lei ${ }^{\circ} 8.828$ reconheceu o ME como instituição extraescolar.

A nível mundial, o ME é gerido pela Organização Mundial do Movimento Escoteiro (OMME), que é apartidária, não governamental e composta por 161 Organizações Escoteiras Nacionais, localizadas em 223 países e territórios com mais de 40 milhões de membros voluntários, sendo 80 mil brasileiros. Além disso, a OMME é uma das 130 organizações não governamentais mundiais com status consultivo geral no Conselho Econômico e Social (Ecosoc) e desenvolve projetos em parceria com a Organização Internacional do Trabalho (ILO); o Programa das Nações Unidas para o Meio Ambiente (Unep); a Organização das Nações Unidas para a Educação, a Ciência e a Cultura (Unesco); e o Fundo das Nações Unidas para a Infância (Unicef) (Wosm, 2016).

\section{PROJETO EDUCATIVO}

O Escotismo tem como missão contribuir para a educação de jovens para ajudar a construir um mundo melhor, no qual as pessoas se sintam plenamente realizadas e possam desempenhar um papel construtivo na sociedade. Para atingir esse objetivo, o Projeto Educativo do ME conta com a colaboração de adultos voluntários os quais 
utilizam o Método Escoteiro, um sistema de desenvolvimento progressivo que promove um ambiente de aprendizado com os seguintes elementos estruturantes: a) adesão à Promessa e Lei Escoteira em que estão expressos princípios que guiam os escoteiros; b) aprender fazendo, pelo qual os jovens aprendem com sua própria observação, elaboração e experimentação e descobrimento; c) sistema de equipes; d) elementos simbólicos que estimulam a imaginação e ajudam a promover o senso de pertencer a um grupo de iguais; e) progressão pessoal; f) vida ao ar livre; g) suporte dos adultos (Wosm, 2016).

As atividades escoteiras são realizadas por faixa etária, sendo que cada uma recebe o nome de um Ramo (Tabela 1), no qual existem objetivos específicos de desenvolvimento pessoal estruturados nas áreas: Físico, Afetivo, Caráter, Espiritual, Intelectual, Social (F.A.C.E.I.S.). Para mais detalhes sobre os ramos, vide a tabela a seguir.

Tabela 1. Organização por faixa etária no Movimento Escoteiro e foco das atividades.

\begin{tabular}{|c|c|c|}
\hline RAMO & GRUPO & FAIXA ETÁRIA / ATIVIDADES \\
\hline Ramo Lobo & Alcateia & $\begin{array}{l}\text { Para meninos e meninas entre } 6,5 \text { e } 10 \text { anos, chamados de Lobinhos e } \\
\text { Lobinhas. Usa como marco simbólico } O \text { Livro da Selva de Rudyard } \\
\text { Kipling. As atividades incentivam a socialização pela diversão e } \\
\text { execução de tarefas em equipes. }\end{array}$ \\
\hline $\begin{array}{c}\text { Ramo } \\
\text { Escoteiro }\end{array}$ & $\begin{array}{c}\text { Tropa } \\
\text { Escoteira }\end{array}$ & $\begin{array}{l}\text { Para meninos e meninas entre } 11 \text { e } 14 \text { anos, chamados de Escoteiros e } \\
\text { Escoteiras. É baseado no estudo da natureza, vida mateira, exploração, } \\
\text { campismo, navegação e conquista do ar, além de ser fundamentado na } \\
\text { vida em equipe e participação comunitária. }\end{array}$ \\
\hline Ramo Sênior & Tropa Sênior & $\begin{array}{l}\text { Para meninos e meninas entre } 15 \text { e } 17 \text { anos, chamados de Seniores e } \\
\text { Guias. Tem suas atividades em torno dos quatro desafios: físico, } \\
\text { mental, espiritual e social, atendendo às características da idade de } \\
\text { autoafirmação, com intenso desenvolvimento físico e intelectual. }\end{array}$ \\
\hline Ramo Pioneiro & Clã Pioneiro & $\begin{array}{l}\text { Para jovens de } 18 \text { a } 21 \text { anos, chamados de Pioneiros e Pioneiras. É uma } \\
\text { fraternidade ao ar livre e serviço ao próximo, funcionando como um } \\
\text { centro de interesses, de realização, de mútua ajuda e de serviço } \\
\text { comunitário, promovendo atividades de campismo, excursionismo e } \\
\text { ecológicas, culturais e sociais, estimulando o jovem a evoluir em } \\
\text { espiritualidade e perfeição humana e atingir a maturidade como } \\
\text { cidadão feliz e eficiente. }\end{array}$ \\
\hline
\end{tabular}

Extraído de: www.escoteiros.org.br. Acesso em: $1^{\circ}$ mar. 2016.

Além das diversas atividades realizadas semanalmente, podem ocorrer também atividades de longa duração em proximidade a ambientes naturais com poucas modificações antrópicas. Tais atividades são de duas modalidades principais. A primeira 
são os acampamentos, nos quais são montadas áreas para cozinhar, lavar e dormir em um lugar fixo. A segunda modalidade são as jornadas, nas quais os jovens, a partir dos 15 anos, fazem trilhas com duração de alguns dias e levam nas mochilas que carregam todo o equipamento necessário para comer e acampar, tendo pouco acesso a infraestruturas e dormindo cada dia em um lugar diferente. Podem ser feitas a pé ou com outros meios de locomoção como bicicletas e canoas.

Ao realizar essas jornadas no ME, os jovens passam por diversas experiências que podem ser similares às descritas por Ferreira (1998), que conduziu uma investigação qualitativa com 5 caminhantes para identificar os elementos que os participantes notavam do ambiente ao longo das trilhas. Foram encontrados 4 temas recorrentes: o ambiente natural e físico; condições das trilhas; preparação física e psicológica individual; e aspectos sociais que vão desde a interação entre os membros do grupo até o impacto da ação humana no meio ambiente.

\section{Educação ambiental no Movimento Escoteiro}

O Escotismo utiliza a definição da Organização das Nações Unidas para Educação, Ciência e Cultura (Unesco) e se caracteriza como movimento de educação não formal por promover atividades educacionais organizadas fora do sistema formal e que se destina à aprendizagem de um grupo com objetivos identificáveis (Alliance of Youth CEOs, 1997). A Lei 9.795 de 27 de abril de 1999, em seu Art 2º diz:

A educação ambiental é um componente essencial e permanente da educação nacional, devendo estar presente, de forma articulada, em todos os níveis e modalidades do processo educativo, em caráter formal e não-formal.

Dessa maneira, pelo seu caráter de educação não formal, o Movimento Escoteiro deve promover a educação ambiental. No entanto, a literatura do campo de pesquisa em educação ambiental tem demonstrado que não existe uma única concepção de Educação Ambiental. Krasilchik (1986, 1994) já apontava essa definição como objeto de intensa controvérsia, não só no nosso país como também no âmbito internacional. Essa autora aponta o fato de que se agrupam sob a denominação Educação Ambiental atividades muito variadas, tanto em conteúdo como em valores. Carvalho (2002), procura tecer algumas reflexões a respeito do que chama "acontecimento ambiental", definido como "a emergência de um campo contraditório e diversificado de discursos e valores que 
constituem um amplo ideário ambiental” (p. 114). Essa diversificação também chegou aos fazeres educacionais relacionados à questão. Para a autora, a construção de uma prática educativa nomeada como EA ganha sentido "como parte da estruturação do campo ambiental e dos contextos políticos e culturais que este articula", afirmando que:

A EA está profundamente marcada pelos limites e possibilidades, bem como pelas disputas internas e externas do campo. É neste contexto de disputas que vão se delinear as diferentes ênfases e compreensões acerca da problemática ambiental e, por conseguinte, dos conceitos, programas análises pedagógicas e políticas voltadas para a intervenção em EA. (Carvalho, 2002)

Após investigações com diferentes projetos de EA, Sauvé (2005) aponta a existência de 15 correntes de educação ambiental:

correntes que têm longa tradição: naturalista, conservacionista, resolutiva, sistêmica, científica, humanista, moral/ética;

correntes mais recentes: holística, biorregionalista, práxica, crítica, feminista, etnográfica, da ecoeducação, da sustentabilidade.

Embora no contexto escolar as orientações dos documentos têm se orientado para correntes mais críticas, no contexto não formal a diversidade é muito maior. No caso do movimento escoteiro, para nortear as atividades, existe o Programa Mundial Escoteiro de Meio Ambiente (PMEMA) que orienta e fornece recursos para o desenvolvimento da educação ambiental. Um dos recursos é a Insígnia Mundial de Meio Ambiente (IMMA), com sugestões de atividades para que os jovens incorporem em seu cotidiano princípios básicos, como a reciclagem e o campismo, sem destruir o meio ambiente. Para a conquista desta insígnia, o jovem deve realizar atividades nos seguintes temas:

1. A humanidade e os sistemas naturais têm de ter água potável e ar puro.

2. Existência de hábitats naturais suficientes para a sobrevivência de espécies nativas.

3. O risco de substâncias perigosas para a população e para o ambiente deve ser minimizado.

4. As melhores práticas ambientais devem ser utilizadas.

5. A Humanidade deve estar preparada para responder aos desastres ambientais e às catástrofes naturais.

A EA também é desenvolvida a partir de atividades específicas em cada faixa etária. Para os jovens do Ramo Sênior, é previsto, na área Social, saber identificar os 
principais problemas que afetam o meio ambiente na comunidade em que se encontra. Outro objetivo relacionado ao meio ambiente é da área Física, na qual o jovem deve participar de "uma jornada de pelo menos $15 \mathrm{~km}$ a pé ou de embarcação, ou ainda 30 $\mathrm{km}$ de bicicleta, acampando e preparando suas refeições durante o trajeto" e realizar pelo menos 4 tarefas dentre: a) Estudo da fauna e flora; b) Estudo dos recursos minerais; c) Meios de transporte; d) Educação; e) População (aspectos históricos e culturais); f) Turismo; g) Recreação e lazer; h) Saúde; i) Comércio; j) agronomia; k) Indústria; 1) Impactos Ambientais provocados pelo Homem (UEB, 2015).

Outras maneiras de se trabalhar a questão ambiental foram documentadas por Silva (2012), que entrevistou escotistas, adultos que atuam diretamente com os jovens escoteiros, de 10 cidades do Estado de São Paulo para saber como eram abordados com os jovens temas de Botânica, Ciências da Terra e Zoologia. Entre as dinâmicas, destacam-se: conquista de especialidades, atividades de sensibilização ambiental, plantio de árvores, reconhecimento de animais e plantas e discussões sobre os temas.

Importante ressaltar que os adultos que promovem atividades para os jovens escoteiros são voluntários e têm diferentes níveis de escolaridade e formações profissionais. Por essa característica, apesar de existirem materiais que norteiam as atividades, é de se esperar que a educação ambiental seja promovida de diversas maneiras e, consequentemente, com diferentes concepções de meio ambiente. Buscando analisar essas concepções, utilizamos contribuições do sistema de representações sociais de meio ambiente proposto por Reigota (1995), baseado nas reflexões de Serge Moscovici, entendendo representações sociais como "um conjunto de princípios construídos interativamente e compartilhados por diferentes grupos", por meio do qual podem compreender e transformar a realidade de diferentes formas.

Pensando na grande variedade de atividades proporcionadas pelo Movimento Escoteiro, faz-se necessário investigar as concepções dos escoteiros que participam dessas atividades, a contribuição das atividades de longa duração para educação ambiental dos jovens em termos de conceitos, valores e formas de participação diferenciadas no cotidiano, bem como os motivos que os levam a participarem voluntariamente das atividades. A partir das concepções e práticas relatadas, buscamos especificar o tipo de educação ambiental que está mais presente a esse grupo e como ela poderia ser ampliada. 
ISSN- 1413-8638

E-ISSN - 2238-5533

v. 22, n. 2, p. 245-261, 2017

\section{METODOLOGIA}

A coleta de dados foi feita no primeiro semestre de 2016, por meio de questionário com perguntas abertas com jovens do Ramo Sênior, de um Grupo Escoteiro localizado na cidade de São Paulo. Antes da coleta de dados, o questionário foi encaminhado para a Diretora Técnica e o Presidente do grupo escoteiro para aprovação. $\mathrm{Na}$ data da coleta, inicialmente, os participantes foram informados que a pesquisa era parte de uma iniciação científica de graduação, que não haveria qualquer identificação e que a participação era voluntária. Além disso, deveria ser respondida individualmente, sendo disponibilizados 40 minutos. A composição dos entrevistados era de 10 meninas e 5 meninos, com média de 16 anos de idade e com média de participação no movimento escoteiro 5 anos.

As respostas dos questionários foram transcritas integralmente e analisadas seguindo os passos da Análise de Conteúdo de Bardin (1977), que por meio de procedimentos sistemáticos e objetivos categoriza unidades de texto que se repetem para inferir conhecimentos dos sujeitos expressos nas mensagens. Para realizar a Análise de Conteúdo (AC) foram realizadas as seguintes etapas: a) Pré-análise: atribuição de um código identificador para cada entrevistado (E-número), transcrição literal de todas as respostas do questionário e leitura flutuante; b) Exploração do material: identificação das unidades de texto que se repetiam, extração de significados das unidades e organização em categorias para análise; c) Tratamento dos resultados e interpretação: apresentação e interpretação dos dados das categorias e discussão por meio de texto. Para classificar as concepções de meio ambiente dos entrevistados foi utilizada a classificação de representações sociais de meio ambiente de Reigota (1995): Naturalista, Globalizante ou Antropocêntrica. Para esse autor, a concepção Naturalista, evidencia aspectos bióticos e abióticos, na qual o meio ambiente pode ser entendido como sinônimo de natureza; a Globalizante, em que o ser humano tem interações com os aspectos naturais; e, por fim, a categoria Antropocêntrica, na qual predomina a utilização dos recursos naturais pelos seres humanos.

\section{RESULTADOS E DISCUSSÃO}


Antes da pesquisa, pensou-se na possibilidade de que jovens que se engajam em atividades escoteiras o fizeram inicialmente por terem interesse e afinidade por temas relacionados ao meio ambiente. Caso a motivação dos jovens fosse pelas atividades ao ar livre, os dados obtidos poderiam ser tendenciosos em relação à contribuição do Movimento Escoteiro para a Educação Ambiental. Por isso, foi importante analisar os motivos que levaram esses jovens a procurar um grupo escoteiro. Entre os entrevistados 1 não respondeu e, entre os outros 14, alguns assinalaram mais de um motivo, como apresentado a seguir.

Tabela 2. Motivações para procurar o Movimento Escoteiro.

\begin{tabular}{c|c|c|c|c|c|c}
\hline Motivação & Amizades & Natureza & Curiosidade & Valores & Diversão & Pais \\
\hline $\begin{array}{c}\text { Número de } \\
\text { unidades de } \\
\text { análise }\end{array}$ & 4 & 2 & 3 & 1 & 1 & 6 \\
\hline
\end{tabular}

A maioria dos jovens (6) ingressaram no escotismo exclusivamente por causa influência dos pais, mas entre os que optaram pelo escotismo, a maior motivação foram as Amizades, tanto as novas, "fazer novas amizades" (E-9), quanto por "amigo que fazia parte do movimento" (E-10). Além disso, como apenas 2 mencionaram "contato com a natureza" (E-1 e E-8), entende-se que os jovens entrevistados não se tornaram escoteiros por uma motivação ambiental.

Os resultados a seguir são apresentados junto com a discussão e referencial teórico em duas partes. A primeira busca entender quais são as experiências positivas marcantes para os jovens em acampamentos e jornadas; a segunda, se e como a participação nessas atividades influencia na educação ambiental destes jovens.

\section{O que os jovens lembram e valorizam em jornadas e acampamentos}

Quando questionados sobre qual atividade externa mais gostaram entre acampamentos e jornadas e o que as tornou marcante, não houve uma preferência, pois 7 indicaram ter gostado mais de jornadas e 6 de acampamentos. Dois entrevistados relataram gostar de ambos. No entanto, como mostrado a seguir, os motivos apontados para essa preferência foram diferentes. 
Tabela 3. Motivos de preferência por jornadas ou acampamentos.

\begin{tabular}{c|c|c}
\hline Modalidade & Motivo & Número de unidades de análise \\
\hline \multirow{4}{*}{ Jornada } & Ambiente diferente & 1 \\
\cline { 2 - 3 } & Amizades & 3 \\
\cline { 2 - 3 } & Contato com a natureza & 4 \\
\cline { 2 - 3 } & Cultura & 1 \\
\hline \multirow{2}{*}{ Acampamento } & Amizades & 3 \\
\cline { 2 - 3 } & Cultura & \\
\hline
\end{tabular}

Entre os acampamentos, o mais citado foi o $23^{\circ}$ Jamboree Mundial no Japão, evento internacional que ocorreu em 2015, reunindo 33 mil escoteiros de 155 países e territórios $\left(23^{\text {rd }}\right.$ World Scout Jamboree, 2015). Pela programação do evento, os jovens passaram por atividades de sensibilização de temas como paz, ambiente, desenvolvimento, direitos humanos, saúde, benefícios e problemas relacionados à ciência, além de atividades para promoção de culturas, com apresentações de dança e música de todos os países e uma feira gastronômica. Dessa maneira, pode-se entender melhor porque as motivações levantadas estão relacionadas a Amizades e Cultura.

[..] conhecer um pouco da cultura de outro país e conhecer escoteiros do mundo inteiro! Acho que foi isso que tornou essa experiência tão marcante, conhecer escoteiros de outros países, conversar com eles [...] (E-5)

[gostei mais do] Jamboree por causa das amizades e novas culturas e pessoas de outros países. (E-9)

[...] Foi uma experiência inesquecível pois haviam muitas pessoas de lugares do mundo todo com coisas em comum, o escotismo. Com isso, nós podíamos trocar histórias, distintivos e experiências. (E-11)

Entre os entrevistados que escolheram as jornadas como atividades externas mais marcantes, a motivação Amizades também aparece como fator determinante. Interessante observar que fora do movimento escoteiro isso também ocorre, pois em um trabalho sobre viagens de campo com pernoite, Cappadocia (2009) encontrou resultados semelhantes com jovens do Ensino Médio. Eles relataram que uma das consequências dessas atividades é o fortalecimento e a formação de novas amizades e que o desenvolvimento dessas amizades se tornava mais forte com desafios e grandes esforços. No escotismo, as jornadas proporcionam desafios físicos e cognitivos maiores do que em acampamentos devido à convivência intensa entre os membros do grupo, ausência de infraestrutura, à duração da atividade, às condições climáticas imprevisíveis 
e ao ambiente desconhecido. Mesmo assim, as jornadas são vistas como positivas e para os entrevistados destacam-se as Amizades e a relação entre jovens e adultos.

[..] Atividades assim qualquer um aprende muito e cria amizades e experiências únicas, muito diferente das interações do dia-a-dia. [...] todos tinham que trabalhar juntos para fazer não só as coisas mais simples como montar as redes e fazer refeições, mas também aprendemos juntos, como andar de canoa. (E-2)

[..] essas jornadas nos uniram muito como grupo. (E-3)

[...] fazemos algo na companhia de alguém que te conhece desde a infância, tanto nossos amigos quanto nossos chefes, essas pessoas já conhecem seus defeitos e suas boas personalidades [... (E-4)

Entre os jovens que citaram jornadas como sendo a experiência mais marcante, o motivo mais citado, e que não aparece nas motivações dos acampamentos, é o Contato com a natureza. Isso pode ter se mostrado mais relevante em jornadas porque os jovens passaram por áreas de preservação e por áreas pouco acessíveis, com raras modificações antrópicas, contrastando com a paisagem urbana em que está inserido o grupo escoteiro.

[...] foi uma atividade em que eu me senti isolada em maior contato com a natureza $[\ldots](\mathrm{E}-2)$

[...] outra razão foi que dormimos ao ar livre em redes, isso proporcionou a nós uma certa ligação com a natureza. (E-6)

[...] foi a primeira vez que andei na chuva. (E-8)

Todos os entrevistados responderam que recomendariam acampamentos e jornadas para colegas, sendo as justificativas muito parecidas com os motivos que tornam essas experiências marcantes, principalmente relacionadas ao Contato com a natureza e Amizades. Porém, um fator exclusivo e importante de recomendação dessas atividades está ligado a um sentimento de realização e conhecimento pessoal:

[...] é uma emoção tão grande chegar aonde nós chegamos que é difícil descrevê-la. É um sentimento de vitória e felicidade juntas, de que você quebrou barreiras. (E-6)

[...] são atividades incríveis fisicamente e mentalmente. Os lugares são fantásticos e você, ao chegar no topo das jornadas, vê que você é capaz de fazê-la. (E-11)

[...] você muda muito com as caminhadas, se conhece melhor. (E-15)

Por meio dessas respostas, entende-se que o escotismo tem um alinhamento entre seu Projeto Educativo e as experiências dos jovens nessas atividades, pois alcançou objetivos propostos para esta faixa etária referentes ao Marco Simbólico do Ramo Sênior de superação de desafios: "se conhecer melhor, testar seus limites, aceitar e aprimorar suas características pessoais, se desafiar constantemente” (UEB, 2015). 


\section{A relação entre a participação em jornadas e acampamentos e a educação ambiental}

Com o objetivo de compreender a contribuição das atividades ao ar livre de longa duração na educação ambiental dos jovens, foram investigadas: as concepções de meio ambiente; se as atividades escoteiras contribuem para aprendizagem de conceitos e atitudes; e se aquilo que os jovens aprendem é utilizado no cotidiano ou limita-se às atividades escoteiras.

As concepções de meio ambiente dos entrevistados foram classificadas em duas categorias: Naturalista com 7 respostas e Globalizante com 8 respostas, mostrando, como era de se esperar, que não há consenso entre os jovens mesmo tendo participado das mesmas atividades. Na categoria Naturalista, foram incluídas respostas em que o ambiente é visto como natureza intocada e exclui o ser humano, ou os humanos não são mencionados como "seres vivos", por exemplo:

\footnotetext{
[...] ao meu ver, meio ambiente é o lugar natural onde se encontram a fauna e flora naturais do local sem a intervenção humana (E-11)

$\mathrm{O}$ meio ambiente é basicamente tudo ligado à natureza, as árvores, os animais, os seres vivos em geral, além dos lagos, rios, mares, etc. (E-5)

Eu entendo que meio ambiente é onde todos os seres vivos vivem e exploram. (E-6)

Seria os animais e plantas. (E-10)
}

Entre os entrevistados que apresentaram uma visão um pouco mais globalizante de meio ambiente, por se inserirem e aos seres humanos como parte desse meio. No entanto, aspectos socioambientais, que caracterizam essa representação, não foram identificados. O mais recorrente (5) foram respostas bem amplas que usaram frases como "onde vivemos" ou "local que nós vivemos até onde outros seres vivos vivem" (E-4). As outras 3 respostas apresentaram a caracterização de meio ambiente com a presença humana:

O lugar onde vivemos e toda a fauna e flora. (E-7)

[...] é o espaço onde vive os seres vivos. Animais, pessoas, plantas, água (rios, lagoas e etc.), o clima, tudo faz parte do meio ambiente (E-1)

[...] Um lugar onde os animais vivem e convivem com nós e a natureza. (E15)

Em relação à outros estudos sobre concepções de meio ambiente de jovens, Santos (2010) encontrou uma visão Naturalista em $70 \%$ dos alunos de Ensino Fundamental I, já Bergmann \& Pedrozo (2007) descreveram que $83 \%$ dos alunos do 
Ensino Fundamental II e 96\% dos alunos de Ensino Médio relataram uma visão de meio ambiente sem intervenção humana. As ideias encontradas nesta pesquisa são concepções de meio ambiente de jovens que estão no Ensino Médio, mas, diferentemente dos trabalhos citados, não houve uma predominância tão grande da concepção apenas Naturalista, sendo necessários mais estudos para entender a formação dessas concepções em jovens escoteiros.

Quando os jovens foram questionados sobre a contribuição das experiências escoteiras na aprendizagem de conceitos sobre a questão ambiental, apenas um entrevistado mencionou um conceito, "Nome de árvores e espécies" (E-3).

Entre os demais, 2 respostas eram vagas e outros 7 descreveram atitudes em vez de conceitos, por isso foram analisadas junto com as respostas referentes à contribuição das atividades escoteiras para atitudes ambientais melhores. Pela característica do Método Escoteiro de aprender pela prática, pode-se entender porque os jovens associam muitas atitudes ao seu aprendizado e têm dificuldade em recordar conteúdos conceituais.

Em relação à contribuição das atividades escoteiras para atitudes ambientais melhores, foram mencionados a relevância de tipos específicos de lixo serem descartados nas áreas naturais em que foram feitas as atividades:

[...] Entender porque não se joga nem o papel higiênico no chão, mesmo sendo "pura celulose", entender que não é pura celulose. A gente dá um sentido para muita coisa que ouve a vida inteira e acha que é "regra". Entender faz parte do processo (ou é o processo) de conscientização que todos falam e pode ser bem simples. (E-14)

Evito jogar sementes de frutos em parques de preservação ambiental (E-12)

Além destes, outros 7 sujeitos investigados disseram ter cuidado com o lixo, dos quais 5 atribuíram essa atitude à participação de acampamentos e jornadas, como pode ser observado nas seguintes respostas:

[...] através dessas experiências que aprendi a importância de jogar lixo no local certo. Você aprende o impacto das suas ações no meio ambiente. Hoje, eu sempre jogo o meu lixo, quando consigo eu reciclo e se eu vejo um lixo jogado no chão eu pego e jogo no local certo. (E-2)

[...] quando estamos num lugar sem lixo jogado nos sentimos melhores. Tento sempre que possível recolher lixo do chão. Me preocupo mais com o destino que o lixo que eu produzo irá seguir e tento manter o meio ambiente que eu frequento sempre limpo. (E-7)

As experiências influenciam nas minhas atitudes ambientais. Por exemplo, em jornadas, quando frisamos que não podemos deixar lixo no caminho, coloco isso em prática no dia a dia, carregando meu lixo comigo quando não 
há lixeiras e descartando em casa. Atualmente, sou muito rígida quanto à separação do lixo reciclável e orgânico. (E-8)

[...] se você sujar o ambiente você vai ver como que estraga o local. Por exemplo: em um acampamento, o ambiente é onde você está acampando, se você sujar, você vai ficar em um lugar sujo. Assim você percebe a importância e os impactos de um ambiente limpo/sujo. (E-11)

Por meio dessas respostas, os jovens expressaram que as atividades ajudam a entender de forma imediata as consequências das suas ações ("se você sujar, você vai ficar em um lugar sujo") e também que as atitudes praticadas nas atividades são colocadas em prática no cotidiano.

\section{CONCLUSÃO}

As atividades externas - acampamentos e jornadas - marcam positivamente os jovens por diversos motivos. Dessa maneira, a aplicação do Método Escoteiro levou ao alcance de diferentes aspectos do desenvolvimento pessoal dos jovens, os quais são propostos pelo escotismo, os F.A.C.E.I.S. Nos acampamentos, o desenvolvimento Social e Afetivo aparece como mais evidente, por outro lado, em jornadas, apesar da parte Social ser evidente, o contato e sensibilização com a natureza foi o fator mais relevante. Isso indica que, em jornadas, há um maior potencial para tratar de assuntos relacionados aos aspectos naturais do meio ambiente, mas que discussões articulando as questões sociais e afetivas às experiências de contato com a natureza das jornadas precisariam estar mais presentes. Importante salientar que jornadas não fazem parte das atividades regulares previstas para jovens menores de 15 anos. Assim, os educadores do movimento escoteiro devem se atentar para os potenciais de sensibilização e educação ambiental nos acampamentos, pois devem ocorrer em todas as fases de desenvolvimento dos jovens.

Nas concepções de meio ambiente, não foram encontrados exemplos de visões Antropocêntricas. Houve um balanço entre as concepções Naturalista e Globalizante, mas estas não seguem os valores encontrados para jovens da mesma faixa etária em outros trabalhos da literatura. A coleta de dados apenas por questionários não permitiu uma análise mais aprofundada dessas concepções, sendo necessárias mais pesquisas para entender se há relação entre as atividades proporcionadas pelo movimento escoteiro e a mudança das visões de meio ambiente. 
Entende-se também que as atividades escoteiras promoveram uma aproximação positiva com o meio natural e uma sensibilização que, somada à mediação dos escotistas, gerou mudanças na visão dos jovens sobre os impactos que causam à natureza. No entanto, os jovens descreveram transpor esses conhecimentos e comportamentos para o dia a dia, destinando apenas às questões de resíduos sólidos, não se apropriando desses elementos para outros aspectos socioambientais, como as diferentes formas de transformação do meio associadas com diferentes culturas e as possibilidades de engajamento individual e coletivo para outros contextos.

Pelos dados coletados, a educação ambiental desenvolvida nas atividades de longa duração do ME para esse grupo parece se enquadrar mais na corrente naturalista, descrita por Sauvé (2005), que tem por objetivo maior a reconstrução de laços com a natureza e parte de abordagens sensoriais, experienciais, afetiva, de imersão e intepretação.

Apesar de identificarmos no Programa Mundial Escoteiro de Meio Ambiente (PMEMA) a necessidade de trabalhar diferentes aspectos da questão ambiental, como, questões sociais, desastres e adaptação, risco de substâncias perigosas para a população e para o ambiente, meio ambiente na comunidade, aspectos históricos e culturais da população, impactos ambientais, entre outros, nas palavras dos jovens investigados esses elementos não foram problematizados. Uma das possibilidades é o fato do ME contar com o trabalho voluntário de adultos que atuam como facilitadores, que precisariam aprimorar suas atividades, uma vez que, face aos desafios ambientais de hoje, atitudes ambientais individuais são insuficientes. Isso pode ser feito por meio da formação de adultos e pela disponibilização de materiais de apoio, para que possam desenvolver atividades que promovam outros elementos da Educação Ambiental. Devem ser realizadas mais atividades com esses formadores e esses com seus grupos para que possam compreender o ambiente como local de complexas relações econômicas, sociais e ambientais, de modo que os jovens possam formar uma visão crítica sobre a relação e a consequência das ações humanas no meio ambiente e participarem mais ativamente de processos de transformação da realidade socioambiental.

Entendemos que são trazidos desafios adicionais aos seus protagonistas em atividades de educação ambiental, que se referem a possibilidades de identificação e 
construção de materiais, projetos e práticas a partir de perspectivas que se pautem em elementos que não trabalhem apenas os problemas ambientais mais superficiais, com propostas de atuação individual, mas que sejam capazes de identificar e problematizar suas causas mais profundas.

\section{REFERÊNCIAS BIBLIOGRÁFICAS}

ALLIANCE OF YOUTH CEOs. "The Education of Young People: A Statement at the Dawn of the 21st Century”. IAA, IFRCS, WAGGGS, WOSM, YMCA, YWCA. 1997.

BARDIN, L. Análise de conteúdo. Luís Antero Reto e Augusto Pinheiro (Trad.). São Paulo: Martins Fontes, 1977.

BERGMANN, M., \& PEDROZO, C. D. S. Percepção Ambiental de Estudantes e Professores do Município de Giruá, RS. Revista eletrônica do Mestrado em Educação Ambiental, Rio Grande, 19, $139156,2007$.

CAPPADOCIA, H. Do overnight field trips make a difference?: Perspectives from women who know. 2009. 209 f. Tese (Doutorado). Royal Roads University, 2009.

CARVALHO, I. C. M. O "Ambiental" como valor substantivo: uma reflexão sobre a identidade da educação ambiental. In: Sauvé, L.; Orellana, I.; Sato, M. Textos escolhidos de educação ambiental: de uma América a outra. Montreal, Publications ERE - UQAM, 2002, Tomo I, pp. 85-90 (versão em português).

FERREIRA, G. Environmental Education through Hiking: a qualitative investigation. Environmental Education Research, London, v.4, n. 2, p. 177-185, 1998.

KRASILCHIK, M. Educação ambiental na escola brasileira - passado, presente e futuro. In: Ciência e Cultura 38(12), dezembro 1986.

Jan./Jun. de 1994.

Educação Ambiental. In: Ciência e Ambiente. São Paulo, n. 8,

REIGOTA, M. Meio ambiente e representação social. São Paulo: Cortez, 1995, p. 6587.

SANTOS, A. M. B., Tagliani, P. R. A., \& Vieira, P. H. F. Educação ambiental em Garopaba: a visão dos professores e alunos do ensino fundamental local. 2010. Revista eletrônica Mestr. Educ. Ambient., 24, janeiro a julho de 2010, 219-232.

SAUVÉ, L. Uma cartografia das correntes em educação ambiental. In: SATO \& CARVALHO e col. Educação Ambiental: pesquisa e desafios. Porto alegre: Artmed, 2005. p. $17-44$. 
SILVA, C. M. L. A. (2012). Contribuição do Movimento Escoteiro na Educação do Brasil: Aspectos do Projeto Político Pedagógico do Movimento e reflexos na educação para a cidadania. São Paulo: Esc. Artes, Ciênc. e Humanidades, EACH, USP.(Rel. PIBIC).

SILVA, C. M.L.A., \& IMBERNON, R. A. L. Aspectos do projeto político pedagógico do Movimento Escoteiro no Brasil e reflexos na educação ambiental. Terrae Didatica, 10(3), 2014, p. 425-435.

UEB - União dos Escoteiros do Brasil. Escotistas em Ação - Ramo Sênior. Curitiba: Editora escoteira da UEB, 2015.

UEB - União dos Escoteiros do Brasil. Disponível em: <www.escoteiros.org.br/ramos/>. Acesso em: $1^{\circ}$ mar. 2016.

WOSM - WORLD ORGANIZATION OF THE SCOUT MOVEMENT. Disponível em: 〈www.scout.org>. Acesso em: 10 mar. 2016. 


\section{ANEXO - QUESTIONÁRIO}

Idade:

Sexo:

Desde quando você participa do movimento escoteiro?

Das atividades abaixo, quais você já participou?

( ) Acampamento geral ( 2016)

( ) Jornada na Serra dos Órgãos (2015)

( ) Jornada em São Francisco Xavier (2015)

( ) Jornada em Monte Verde (2014)

( ) Expedição de canoa (2014)

( ) Outros acampamentos ou jornadas?

1- O que você entende por meio ambiente?

2- Como você descreve suas atitudes ambientais?

3- Das atividades do movimento que você participou até hoje, quais você mais gostou e por que? O que as tornou marcante?

4- Se houver, descreva experiências (pensamentos, dinâmicas, interações) que ocorrem nessas atividades, mas não acontecem em outras situações fora do movimento escoteiro.

5- Você recomendaria jornadas e acampamentos para seus colegas? Por que?

6- Você acha que essas experiências contribuem para aprender conceitos sobre a questão ambiental? Se sim, quais?

7- Você acha que essas experiências contribuem para atitudes ambientais melhores? Se sim, por que? Dê um exemplo.

8- Se houver, dê exemplos de algumas atitudes suas que mudaram em relação ao ambiente no seu cotidiano por causa da sua participação em acampamentos e jornadas. 